\title{
BMJ Global Health How to set up government-led national hygiene communication campaigns to combat COVID-19: a strategic blueprint
}

\author{
Val Curtis (D , ${ }^{1}$ Robert Dreibelbis, ${ }^{1}$ Myriam Sidibe, ${ }^{2}$ Jason Cardosi, ${ }^{1}$ Jennifer Sara, ${ }^{3}$ \\ Chris Bonell, ${ }^{4}$ Kaposo Mwambuli, ${ }^{5}$ Soma Ghosh Moulik, ${ }^{3}$ Sian White, ${ }^{1}$ \\ Robert Aunger ${ }^{1}$
}

\begin{abstract}
To cite: Curtis V, Dreibelbis R, Sidibe $\mathrm{M}$, et al. How to set up government-led national hygiene communication campaigns to combat COVID-19: a strategic blueprint. BMJ Global Health 2020;5:e002780. doi:10.1136/ bmjgh-2020-002780
\end{abstract}

Handling editor Seye Abimbola

Received 16 May 2020

Revised 11 June 2020

Accepted 15 June 2020

Check for updates

(c) Author(s) (or their employer(s)) 2020. Re-use permitted under CC BY-NC. No commercial re-use. See rights and permissions. Published by BMJ.

${ }^{1}$ Department of Disease Control, Faculty of Infectious and Tropica Diseases, London School of Hygiene and Tropical Medicine, London, England

${ }^{2}$ Harvard Kennedy School, Harvard University, Cambridge, Massachusetts, USA ${ }^{3}$ Global Water Practice, World Bank, Washington, D.C, United States

${ }^{4}$ Department of Public Health, Environments and Society, Faculty of Public Health and Policy, London School of Hygiene and Tropical Medicine, London, England

${ }^{5}$ Project Clear, Dar-es-Salaam, United Republic of Tanzania

Correspondence to

Professor Val Curtis val.curtis@Ishtm.ac.uk

\section{ABSTRACT}

While large-scale changes in population behaviour are required to reduce the transmission of the severe acute respiratory syndrome coronavirus 2 virus, the emergency context is not conducive to the sort of careful communications planning that would normally be required to meet such a task. Rapid strategic communications planning in a pandemic by governments is, however, possible and necessary. Steps include setting up a dedicated communications task force, mobilising partners and resources, developing a creative brief and theory of change and overseeing the creation, testing, roll out and revision of content. In this short guide, we argue that a minimum of strategic planning can be undertaken rapidly, and that good use can be made of simple principles of behaviour change, even during pandemics. Our aim here is to provide a blueprint that governments and their partners, especially in low-income settings, can follow to design, coordinate and resource national communications efforts to combat the COVID-19 pandemic immediately and for the longer term.

\section{BACKGROUND}

Governments across the world are responding to the COVID-19 pandemic with measures that include implementing communications campaigns to promote behaviours that can reduce transmission of the virus. These include hand hygiene, physical distancing, surface disinfection and mask wearing, as well as specific measures for particular populations such as isolation of the vulnerable. However, rapid, population-scale behaviour change, such as that which is required to contain a pandemic, can be difficult to achieve, even in the best of times. Some behaviours may be new, requiring new routines, new infrastructure, new products and new norms. Some behaviours can be infeasible in the socioeconomic context in which they are being expected. On the other hand, outbreaks can also catalyse changes in behaviour. ${ }^{12}$ In the pressured environment of a public health
Summary box

Most country governments are organising communications programmes to promote handwashing, social distancing and other key behaviours in an effort to combat the COVID-19 pandemic.

- Efforts are currently centred around information provision and education and not behaviour change.

- Effective communications need to be organised strategically and professionally, employ rapid formative research, creative professionals, a creative brief and a theory of change and be tested and revised.

- Principles of behaviour change include employing surprise and emotion, and making the target behaviour possible.

- Despite the urgency, strategic communications planning is essential if behaviour change campaigns are to be effective in a pandemic

emergency, it is especially hard to carry out the strategic communications planning that is needed for effective programming, since immediate and urgent responses tend to be prioritised. $^{3}$

Furthermore, it is becoming increasingly clear that communications about COVID-19 will need to be sustained and to evolve until vaccines or other means of bringing it under control can be found. All governments need the capacity to engage in strategic public health communications, emergency or no.

Of course, strategic communications programmes have only a part to play in a national pandemic response; many other measures are needed to help reduce the risk of viral transmission, including changes to social support systems and to the physical environment. It is hard to practice hand hygiene, for example, without Water, Sanitation and Hygiene (WASH) infrastructure and supplies. Efforts to change behaviour may also have negative effects. Physical distancing measures can cause losses to livelihoods (https:// 
Box 1 Ten steps in developing a national

communications strategy for COVID-19 prevention

1. Set up a task force and appoint a national focal person.

2. Mobilise resources and involve the private sector.

3. Define exactly which behaviours need to change and by whom.

4. Review what is already being done internationally and locally.

5. Review what is known about the drivers of these behaviours and rapidly fill in gaps in knowledge.

6. Produce a creative brief and theory of change.

7. Develop a unifying national brand.

8. Develop executions employing the most relevant channels for the target audiences.

9. Rapidly pretest and continually revise content.

10. Deliver, monitor, evaluate and share lessons.

foreignpolicy.com/2020/04/10/poor-countries-socialdistancing-coronavirus/), reduce access to healthcare for other conditions or reduce people's ability to pay for services such as water and sanitation. Nevertheless, coherent communications about expected behaviour remain a prime responsibility of government institutions.

While country or regional governments need to design communications campaigns that are appropriate to their particular contexts, there are some key principles that apply across settings. Here, we set out 10 essential steps in the development of a national communications strategy (box 1) to aid rapid, but strategic, thinking on designing pandemic communication campaigns. In providing this guidance, we draw on the experience of multiple national campaigns on hygiene in domestic settings in low-income countries ${ }^{4-7}$ and a widely used framework for understanding and changing behaviour known as behaviour-centred design (BCD). $\mathrm{BCD}$ provides a generic but theory-based process for designing behaviour change programming. ${ }^{8}$ Our aim here is to provide a short blueprint for countries and their development partners wishing to enhance their national COVID-19 communications activities.

\section{DEVELOPING A NATIONAL BEHAVIOUR CHANGE COMMUNICATIONS STRATEGY}

The steps in the process are shown in Box 1.

\section{Step 1. Set up a communications task force and appoint a national focal person}

While many governments have assigned political responsibility and created high-level committees on the COVID-19 response, these tend to concentrate on urgent matters such as provision of care, supplies and testing. Promotion of daily domestic practices such as handwashing is often seen as lower in priority, but still requires an urgent and specific focus, since such measures are the only effective way to prevent infection in the absence of a vaccine. While existing public health promotion teams will have been mobilised, it can be useful to reinforce them through the designation of a National Focal
Person with sole responsibility for pandemic behaviour change planning. Their role is to champion and coordinate national communications activities. The chosen national focal person will need technical experience in communications, marketing, cross-sectoral coordination and public health, and combine this with personal qualities of energy, persistence, open-mindedness, a problemsolving focus, communications and networking skills and motivational leadership. ${ }^{6} \mathrm{Her} /$ his role is to assure a joined-up approach to national communications across all channels and by all partners (as far as is possible in an emergency). He or she may be seated in the Ministry of Health (MoH) but must coordinate across the full range of ministries and cabinet offices that contribute to the response. Aside from technical leadership, the focal person will need to be able to lead the national effort, bringing together all key stakeholders around a step-bystep strategy and a unifying brand.

The national focal person will need the support of a small, agile, action-oriented, task force to execute the communications strategy. This task force should draw on local skills and resources, but could include the MoH's health promotion unit, private sector representatives, media, behavioural scientists and/or creative and communications specialists and, ideally, one or more members of the target audiences. The task force should not replace, but complement, existing coordinating structures, for example, under the cabinet or the United Nations, and seek to amplify their ability to mobilise expertise, reach and resources under national leadership. An example is the Swaach Bharat Mission which successfully transformed sanitation provision across India by using a task-force, results-oriented, approach; co-opting young, energetic staff to mobilise activity within the bureaucracy of a busy line Ministry. ${ }^{6}$

\section{Step 2. Mobilise resources, including from the private sector}

Financial and human resources are being mobilised globally towards COVID-19 prevention. National governments have the mandate to ensure that these are harnessed towards the Government's agreed goals, that efforts complement each other and that they use evidencebased approaches. Governments can source funds from national budgets, from loans and donations, by switching existing programmes towards the pandemic response and/or by approaching Industry. Some portions of loans and donations are usually dedicated for public communication, which, if not planned strategically, will be reallocated. Countries with well-thought-out communications strategies often find themselves at the head of the queue when applying to banks, multilateral and unilateral donors and granting foundations. The better a country, task force or focal point can organise and articulate what is being asked for, the more, and faster, resources will be forthcoming. For example, funders are seeing disproportionate numbers of applications from countries such as Bangladesh and Pakistan, which have a lot of experience in communications planning. 
Governments are generally used to seeking the support of external agencies such as the development banks, the bilateral donors and the international non-governmental organisations. However, in the current context, mobilising finance may be less of a problem than mobilising human capital. A sophisticated communications campaign needs the support of experts in behaviour, in content development, in media buying, planning and influencing and in monitoring outputs so as to gauge impact. Industry has special skills in this respect. While governments may expect that companies will want to make donations of products such as soap, industry can make a more valuable contribution to the prevention effort-their particular ability in marketing to consumers (behaviour change, by another name). Companies are competing to join the COVID-19 response, and are keen to gain government approval for their efforts, both because it increases their reach and enhances their legitimacy in the social field. ${ }^{9}$

Industry has particular skills and capacities that are invaluable for national communications campaigns. They understand the need for unification around a single 'brand' (in this case the national COVID-19 brand-see step 7, below) and how to create such a thing. They have access to professional creative companies and individuals who can craft messages and bring them to life, ensuring that the content of messaging is not just informational, but surprising, motivating and feasible. ${ }^{8}{ }^{10}$ In other words, ensuring that it is not just the right message that is being diffused but that the message is right. ${ }^{11}$ For example, most current COVID-19 communications efforts are still entirely focused on the provision of information, yet it is doubtful that information alone is sufficient to change behaviour. ${ }^{1}$

Industry also understands media planning, through being able to model how far resources invested in different channels will allow messages to reach a specific set of the target population, and to monitor the reach and effectiveness of their activities. Increasingly, they also understand how to manage communications output, not just through traditional channels such as TV and radio, but via digital and social media as well. In many countries, industry may be the only institutions set up to communicate at the scale that is required in the current crisis. For these reasons, the government team should enlist business help as early as possible. Ministers can begin the process by directly calling on national Chief Executive Officers for help, ideally asking for some delegation of staff time for communications planning purposes.

Government public health authorities may be unused to dealing with private sector players. The national focal person needs to be able to liaise with and speak the language of business, to respect the speed at which business moves (eg, to engage them only in focused meetings to make quick decisions, rather than in prolonged national committee debates), and to recognise that the private sector is competitive, so companies may not collaborate easily. The government team should also recognise that the desire of business to gain visibility and acknowledgement of their efforts is just as legitimate as that of the usual third sector players.

A good example of how business is working together with government and other players to fight coronavirus is the communication campaign developed by the National Business Compact in Kenya, led by the Marketing Society of Kenya. Multiple soap companies (Unilever, Reckitt-Benkeser, Pwani, Mengengai, Pz Cussons) are contributing by giving soap, and by funding a 3-month unbranded campaign through mass media and in digital channels. The national brief was approved by the Ministry of Information, Communication and Technology and all materials were approved by the National Emergency Task Force. The national brief was executed by BBDO who conceived the Komesha Corona (Fight Corona) campaign under the authorisation of the government. The soap companies gave media time during prime-time $\mathrm{TV}$, as well as billboard space and radio placements, and agreed which of their joint influencers could be used to front the campaign. The marketing directors of the soap companies reviewed the campaign and gave feedback. Public Relations and branding of the National Business Compact is being managed on a pro bono basis by Ogilvy (https://www.covid19businessresponse.ke).

Step 3. Define which behaviours need to change and by whom While it may initially seem obvious, the question of exactly which behaviours need to change is a difficult one. First, evidence as to what works well to prevent community transmission of COVID-19 in the community is scarce. There is controversy, for example, about the utility of wearing of masks, ${ }^{12}$ the feasibility of promoting isolation and shielding strategies and the role of contaminated surfaces and objects in viral transmission. Scientific evidence on COVID-19 transmission is being published at an unprecedented rate, but there are still many uncertainties.

Two key behaviours around which there is public health consensus are hand hygiene and physical distancing. Handwashing with soap is a particularly plausible intervention in all countries, with a moderate level of evidence that it can be effective in preventing transmission of respiratory viruses. ${ }^{13}{ }^{14}$ It can also have other benefits. ${ }^{15}$ Unfortunately, we know that the practice is not common in domestic settings in normal times ${ }^{15}$ and is difficult to promote, especially when soap and facilities such as water are scarce or inconvenient to use. However, during a pandemic, motivation to practice may increase. ${ }^{2}$

Physical distancing is a novel behaviour, which contradicts normal tendencies for people to come into contact, and so interrupts normal routines and has few mental cues. Distancing may also be extraordinarily difficult in the context of the informal economies of many lowincome countries, where crowded markets, workplaces, transport hubs and water points form the essential scaffold of economies and livelihoods.

Our current best guess for priority control measures against severe acute respiratory syndrome coronavirus 


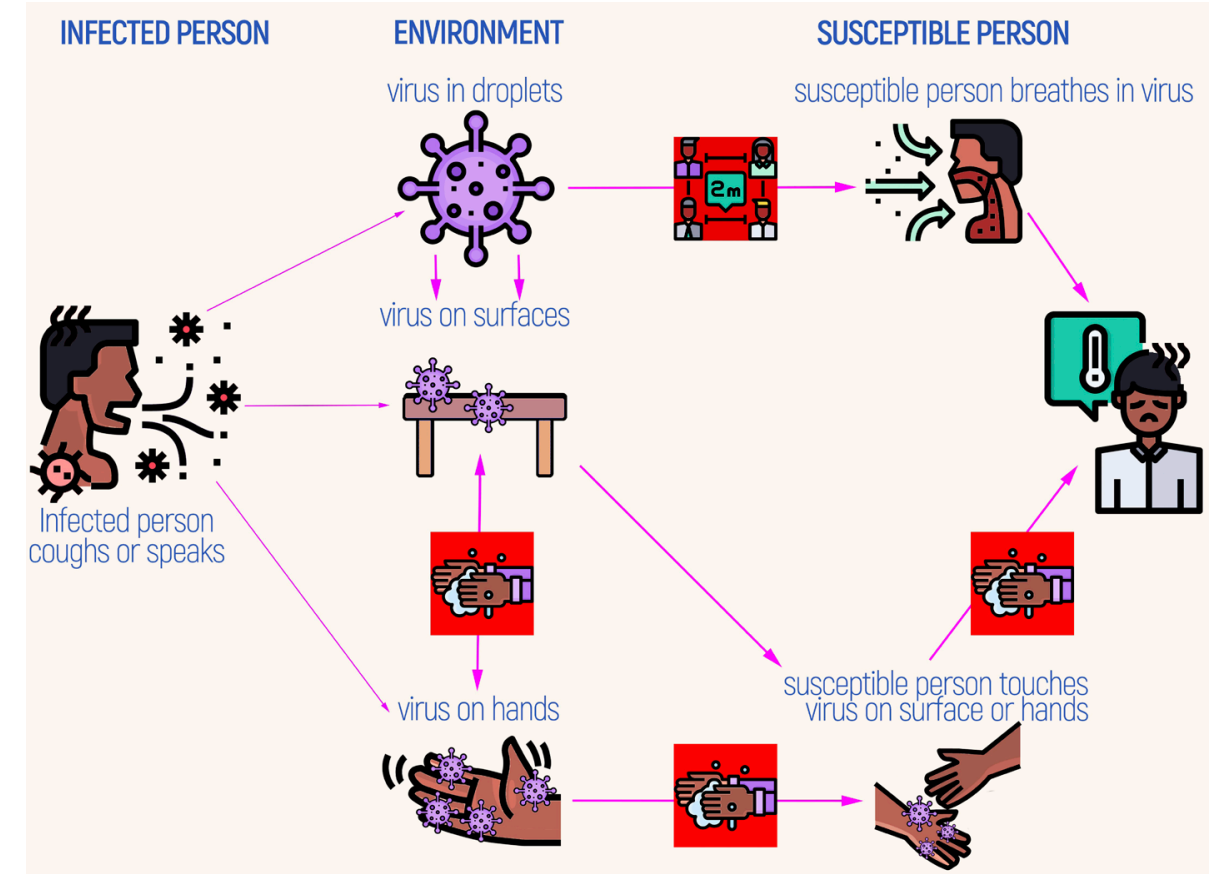

Figure 1 Breaking the chain of COVID-19 transmission in the community (distancing and hand hygiene preventive measures shown in red, not including surface hygiene and mask wearing).

2 transmission are summarised in figure 1, which shows how physical distancing and regular handwashing at key moments are key to cutting the transmission routes of the virus.

Different behaviours are also expected from different subpopulations. The vulnerable, including the poorest, the elderly, the immuno-compromised and the disabled need most protection, but often they are in circumstances that make them the hardest to shield from the virus. Key workers need protection in the workplace, but the conditions for physical distancing may not be in place.

International guidelines, from $\mathrm{WHO}$, for example, should form the basis of behavioural targeting, but with careful consideration of what is feasible and sustainable in local circumstances. Advice will also change as more evidence comes in. It is vital that government agree on the key behaviours they wish to promote. These should be simple, feasible and coherent. For example, in the UK clear mass messages, such as 'stay at home' and 'wash your hands' have been effective, with recent polling showing $94 \%$ of respondents saying they know what they need to do to limit their risk of contracting coronavirus and $98 \%$ of people feeling well informed about physical distancing and how it applies to them.

\section{Step 4. Review what is already being done internationally and locally}

While every country has different contexts and needs, the simple principles of blocking the transmission of the virus from one human to another remain the same everywhere (figure 1). The epidemiological consequences, however, differ from country to country depending on the demographic, social and physical circumstances and vulnerabilities of the population, as well as by the level and types of control efforts.

Country programmes need to be aware of global developments, without being overwhelmed by the plethora of information appearing on huge numbers of platforms from many different sources. Most available information is currently focused around the needs of richer countries, which have experienced the virus first, and it is hard to find reliable information relevant for low-income settings. The most authoritative sources should be sought out. These include established, reputable newspapers and news sites on digital media. The most reliable sources are generally academic in nature, but may require prior familiarity with the clinical, modelling, epidemiology and disease control sciences to interpret and it can be hard to see how research findings apply practically. Furthermore, much is being published on COVID-19 without peer review, which means that conclusions cannot always be relied on. Up-to-date research can be consulted at: https://www.ncbi.nlm.nih.gov/research/coronavirus/, https://www.thelancet.com/coronavirus, https://coronavirus.jhu.edu/map.html. Other more user-friendly sources include https://www.thecompassforsbc.org/ trending-topics / covid-19-resources-social-and-behaviorchange, https://community.ready-initiative.org/ and the COVID-19 Hygiene Hub https://hygienehub.info/ COVID-19. These initiatives provide curated reviews and tools, up-to-date evidence summaries and resources to help translate new findings into practical implementation strategies.

A key role for one member of the national task force is to keep under review what is being produced. Good 
efforts should be highlighted and multiplied, while misinformation needs to be spotted and countered speedily. A press subcommittee for the task force can be formed for media advocacy, to encourage responsible journalism. If resources and time allow, a professional PR firm should ideally be brought on board to help to shape the national narrative.

\section{Step 5. Review what is known about the drivers of risk behaviours internationally and locally, and rapidly fill in any gaps in knowledge}

The country task force needs to be aware of current evidence about what drives changes in the behaviours that they wish to see. This is because behaviour is not driven by knowledge alone. An effective national communications plan will need to engage the population with information that is new and surprising so as to get and keep its attention, the communications have to be able to motivate action (revaluation), by making the behaviour something that people will find rewarding to do-for a variety of possible reasons-and above all, the advocated behaviour has to be possible, as infeasible advice is simply counterproductive. ${ }^{8}$

We already know in general what the main drivers of handwashing behaviour during non-pandemic conditions are. First of all, people wish to remove any disgusting material from their hands, whether after the toilet, after sneezing or after contacting greasy or dirty material. ${ }^{4}$ Second, people wash hands as a sign of good manners, for example, to protect others when serving food or shaking hands. ${ }^{16}$ This is, to some extent, enforced by social norms, especially when handwashing takes place in public. ${ }^{17}$ Nurture of offspring and other relatives is also a well-established motive for handwashing. ${ }^{18}$ There is also evidence that handwashing increases in the face of fear of an epidemic, although it may rapidly return to baseline level afterwards. ${ }^{2}$ These are global drivers of handwashing and do not seem to vary much between countries. ${ }^{19}$

While these motives can all be potent divers of handwashing behaviour, it still takes time and effort to wash hands, and the likelihood of compliance is dependent on the ease of performance. While only small amounts of water and soap are needed, when these are expensive, and/or hard to access, the likelihood of handwashing falls dramatically. ${ }^{1}$ National WASH efforts should be ramped up to make domestic water supply more easily available, always with the proviso that this may be hard to achieve for large populations in the short term. There may also be a case for the large-scale production, procurement, placement and management of water tanks and handwash stands, especially for work and educational places (box 2).

Much less is currently known about the drivers of distancing behaviours. Disgust of the possibility of being infected by the emanations of others is a natural response to pandemics, but this is not a recommended route to use in promotion, since any invocation of disgust could led to stigmatisation of individuals. ${ }^{20}$ Such distancing
Box 2 The Water, Sanitation and Hygiene (WASH) response to COVID-19

Safely managed WASH services are an essential part of preventing and protecting human health during infectious disease outbreaks, including the current COVID-19 pandemic. Good WASH and waste management practices, that are consistently applied, serve as barriers to human-to-human transmission of the COVID-19 virus in homes, communities, healthcare facilities, schools and other public spaces. Key priority actions include:

- Provision of safe WASH services in healthcare settings to protect patients, healthcare workers and staff.

- Providing access to WASH facilities in schools, workplaces, markets, prisons, care facilities, transport stations and other areas where people gather.

- Emergency WASH support to the most vulnerable, whether in informal settlements, relief camps or in contexts of displacement due to fragility, conflict and violence.

Adapted from: https://www.worldbank.org/en/topic/water/brief/washwater-sanitation-hygiene-and-covid-19

behaviours also go against a tendency to want to approach and interact with fellow humans, especially in times of distress.

Aside from motives for safer behaviour, national programmes urgently need to learn more about how to make distancing measures feasible in their own socioeconomic contexts. Here local intelligence is critical. Given time and resource, full-scale formative research into current behaviour would be desirable, ${ }^{8}$ but what can be done speedily and rigorously in a pandemic, potentially under lockdown conditions?

First of all, any valid research is better than none. Table 1 provides some suggestions for rapid canvassing of local behaviour and behavioural drivers. The emphasis should be on capturing the voices of those who are less likely to be heard, since decision-makers are generally drawn from urban elites, their anecdotal evidence may not represent what is happening in the general population. Specific research may be needed to understand the problems of particular vulnerable groups, for example, the aged and those with disabilities.

The national task force should commission such rapid research, but also gather reports from other partners with on-the-ground intelligence about existing behaviour and its drivers. A rapid way of extracting salient information is to hold an insight workshop. Here the data are reviewed, then all participants write down on slips of paper any facts that have struck them. These can then be grouped and arranged in order of likely importance. The point of gathering such intelligence is not academic, but to rapidly gain insight as to what is happening, and as to what could cause changes in the desired behaviours ${ }^{21}$ (https://www.lshtm.ac.uk/sites/default/files/2017-03/ BCD20Guide.pdf). For example, an early online insightgeneration workshop held by a design team in Tanzania zeroed in on the strong national identity and shared responsibility for each other. 


\begin{tabular}{|c|c|c|}
\hline Method & Approach & Data \\
\hline 'Teledepths' & $\begin{array}{l}\text { Qualitative in-depth phone interviews with convenience } \\
\text { samples of target audiences, eg, six casual labourers, six } \\
\text { domestic workers, six seniors. }\end{array}$ & $\begin{array}{l}\text { What are you are doing now? } \\
\text { What has changed? } \\
\text { What tools, infrastructure and support are } \\
\text { you employing? } \\
\text { What is helping? } \\
\text { What is making it more difficult? }\end{array}$ \\
\hline Phone polling & Quantitative national telephone polling surveys, repeated. & $\begin{array}{l}\text { Reported behaviour, knowledge, intentions, } \\
\text { trends. }\end{array}$ \\
\hline Citizen science & $\begin{array}{l}\text { Teachers asked to write or film and post-COVID-related } \\
\text { behaviour stories. }\end{array}$ & $\begin{array}{l}\text { Indicators and social and physical context } \\
\text { of behaviour. }\end{array}$ \\
\hline Routine data & $\begin{array}{l}\text { Transport numbers, soap sales, sanitiser sales, google } \\
\text { searches, food market activity, work absentee figures, } \\
\text { school attendance, social media monitoring. }\end{array}$ & Indicators of actual behaviour. \\
\hline
\end{tabular}

\section{Step 6. Produce a creative brief and theory of change}

With the team assembled, target behaviours decided and insights about those behaviours marshalled, it is time to design the communications strategy. Table 2 gives an example of a draft creative brief produced to assist in the development of a communications strategy for COVID-19 in Tanzania. Such creative briefs are central to communications campaigns because they summarise the 'must-have' components for everybody involved. This example includes a problem statement, purpose, objectives, target behaviours, audience data, the persuasive argument, the tone, personality, measures of impact and materials required from the creative team.

In normal times, the creative brief would be sent out to tender for professional creative teams to bid to create a national communications campaign. The best technical and financial proposal would be selected, the company would be contracted and a design process with numerous phases of creation and reverts would be instigated. In an emergency such as this, however, the process may have to be short-circuited. The task force will need to find rapid means to source creative inputs. Help can be sought from the private sector, as set out above, from creative individuals and from international organisations with skills in communications. While all will be used to working from creative briefs, it is important to note that every client and every creative organisation employs different language about the creation of content and the task force will need to devote time to 'getting on the same page'.

Underlying the creative brief is a theory of change. There are many ways of drawing up a theory of change. BCD employs a simple, generic version as shown in figure 2. This sets out how the communications intervention will change the social and physical environment in which people live (including the messaging they see), how this will change something in their minds persuasively (through motivation, beliefs and habits), how this will change their behaviour and how this will reduce the risk of transmission. ${ }^{8}$ The theory of change provides the links in the chain from intervention, which must be surprising, cause revaluation and be possible to perform, to impact and serves to constantly remind the team that if any of the links are broken, the communications chain will be ineffective. It also serves as a guide as to what factors need to be monitored and evaluated throughout the intervention chain and for identifying any unintended harms caused by the intervention. ${ }^{22}$

The basic principles of successful communications are shown under the diagram. Communications have to be surprising, cause revaluation of the behaviour such that individuals will be motivated to act and performance of the behaviour should be enabled (eg, by making it easier to do). We expand on these below:

\section{Surprise}

We know that it is necessary to create communications that attract attention, or they will be ignored. Communications about COVID-19 must be surprising-in the sense of being unexpected in some way. ${ }^{23}$ In a pandemic, this is even more critical, so as to cut through the plethora of messages being transmitted from many sources. The channel can sometimes be surprising-seeing a respected government figure on Instagram, for example, might be a 'first' for many in some countries. Having the Prime Minister of Ethiopia demonstrate how to do handwashing, as part of a '\#SafeHandsChallenge' might be even more unexpected.

Furthermore, individuals only learn from the unexpected, not from things that they know already. ${ }^{23}$ Standard messages must be presented in a new way with a new angle, new connections and new insight. For example, the Nike ad referred to in table 3 is surprising in that it suggests that we can all be champions, even from our bedrooms.

\section{Revaluation}

People do things because they are rewarding. These rewards can be physical, like money or food, or social, like praise or acceptance into a group. These are translated into psychological rewards via the dopaminergic 
Table 2 Example of a creative brief

\begin{tabular}{lll}
\hline Activity name & COVID-19 communication brief & \\
\hline Client name & Tanzania Ministry of Health & National focal person \\
Date & $\mathbf{3 0}$ April 2020 & $555-5555$ \\
Client contact & NAME & NFP@MoH.gov \\
& PHONE & NMAlL
\end{tabular}

\section{Purpose | The problem}

The purpose of this brief is to coordinate the design, planning and execution of compassionate, engaging and empowering communication materials in order to develop and sustain the health behaviours that will stop the spread of COVID-19 disease. The focus is on personal and social protective behaviours such as practising personal hygiene, maintaining physical distance, wearing masks in public and self-isolation in case of symptoms.

\section{Outcome objectives}

Minimising morbidity and mortality from COVID-19 in Tanzania

Communication objectives

\section{What does the communication want to achieve}

Make everyone want to help stop the spread of COVID-19 by practising the personal and social protective behaviours desired by the government.

\section{Campaign audience}

\section{Communication target | who are we trying to reach?}

Primary

- Young people, aged 15-35 years. They are both the most exposed to the economic impact but also have a perception of invulnerability. They are slowest to adopt the behaviours necessary to flatten the curve. And while not as vulnerable as higher risk groups, they are not immune either. Secondary

Seniors and those with chronic health condition most vulnerable to COVID-19.

Potential partners who are willing to support the cause.

Political leaders and government.

Profile of our primary audience:

- Speak and understand the national language and their own vernacular languages.

- Travellers, self-employed and petty traders working hard to secure their future and most susceptible to catching and transmitting COVID-19 (but need practical information about how to safely continue earning a living).

- Families care about protecting their loved ones (but how to do so, practically, is not clear).

- Urban audience currently most at risk have GOOD access to TV, radio and social media via smart phones.

- Rural audience have LOW proliferation of smart phones, little access to social media pages. Fifty per cent listen to radio regularly. TV and cinema are currently watched in public places and information spreads by word of mouth, eg, marketplaces.

\section{Project target | What change are we looking for?}

\section{GET heads of households and families.}

TO practice personal and social protective behaviours in the community, ie, handwashing with soap more frequently, physical distancing, wearing masks in public and isolation of the symptomatic.

BY convincing them that they can help save lives.

Persuasive argument

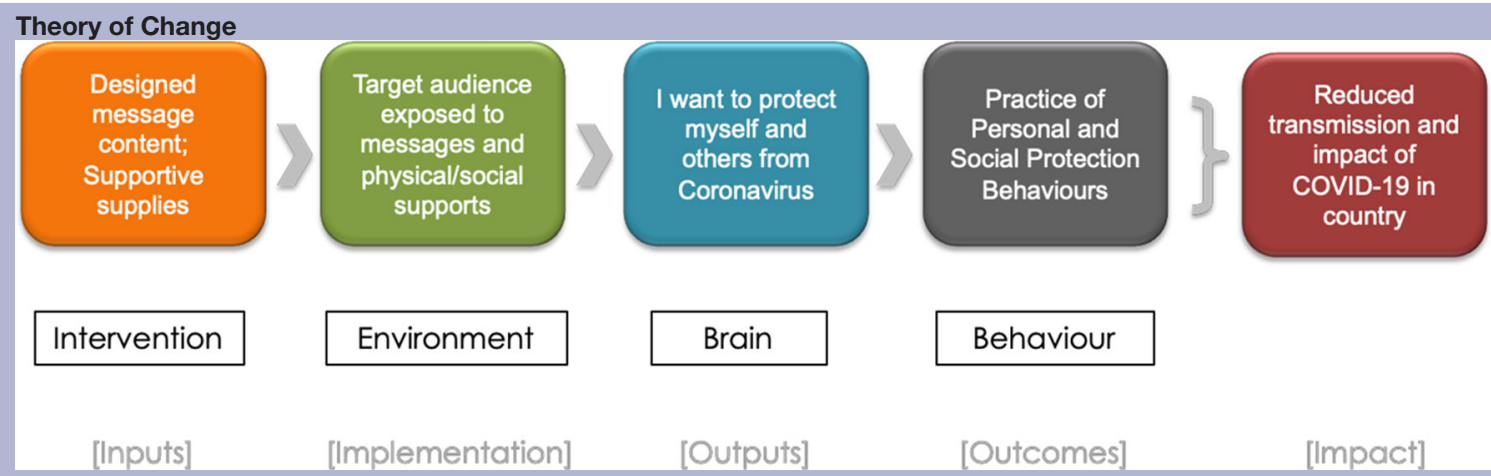

\section{The takeaway | What is the key message?}

We must all protect ourselves and others from the spread of coronavirus.

To reduce this spread we need to act together.

Everyone depends on each other to achieve this.

Therefore, we all have obligations to each other:

"Don't take it lightly, You are depended upon!"

\section{Campaign tone | What traits are we trying to convey?}

Relevance, compassion, empowerment, solidarity.

Campaign personality | What characteristics define the campaign? 


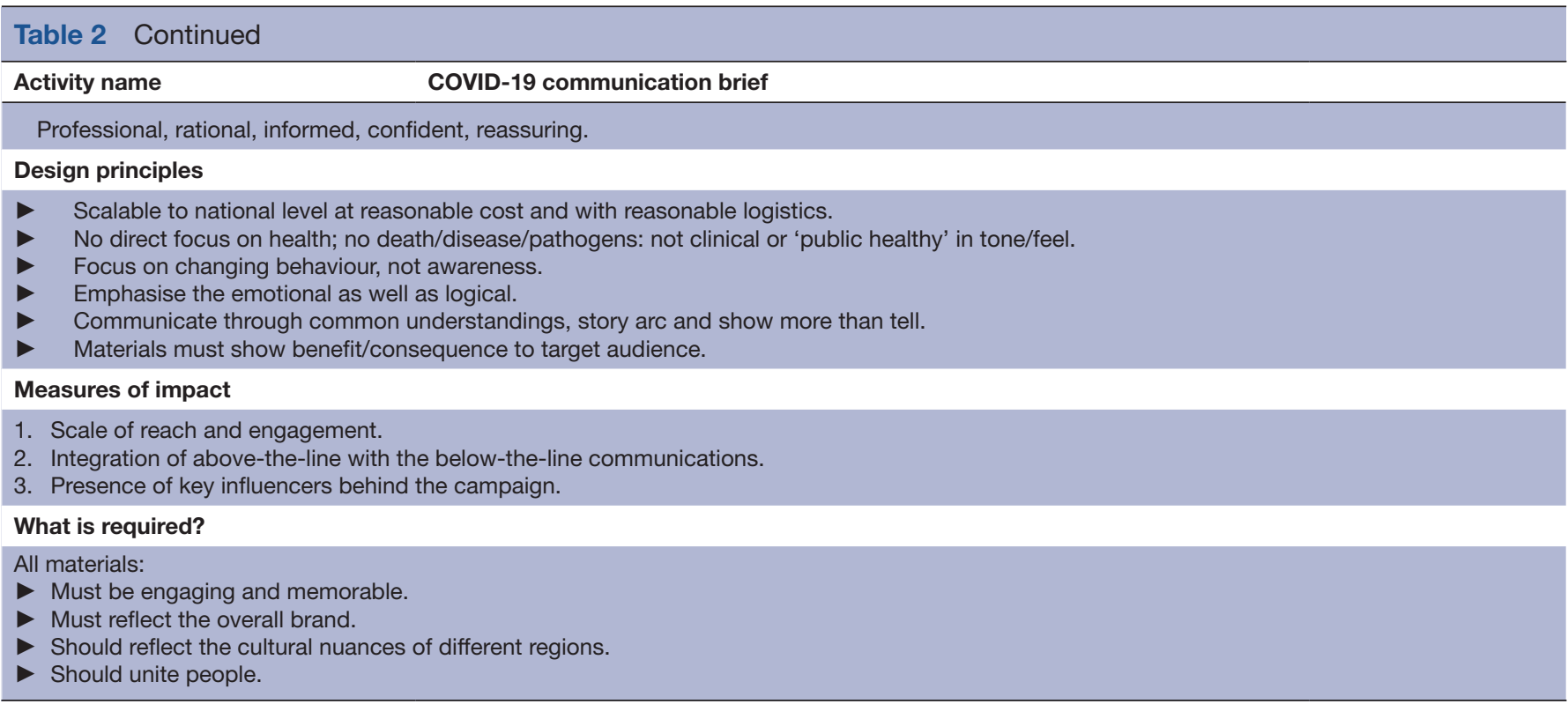

system of the brain. ${ }^{24}{ }^{25}$ Making sure people understand and appreciate the possible physical and social rewards from doing the target behaviours is important. For example, using bar soap to protect one's family is a rewarding activity (the nurture motive), as brought to life in the marketing strategy of Lifebuoy soap (eg, https:// www.youtube.com/watch?v=1XuKc1KyTGM).

People also find it rewarding to carry out activities for the sake of helping others. While people will often readily engage in behaviours to protect themselves in the face of an obvious risk, many of the recommended behaviours are about reducing the likelihood of spreading the virus to others. Luckily, people are not just motivated to help themselves, as altruistic behaviour is a feature of all human societies. ${ }^{26}$ For example, moral elevation is inspired by others' prosocial, selfless acts, and this experience prompts observers to also act with kindness and generosity themselves. ${ }^{27}{ }^{28}$ Constant congratulation of the public for helping others by following recommended measures is a reward strategy used in press briefings by the French government (eg, https://www.youtube.com/ watch? $v=\mathrm{a} 2 \mathrm{fhXo} 4 \mathrm{SzfA})$.

Furthermore, people tend to conform to what their groups are doing by following the norms of those groups. Emphasising new normative standards-such as engaging in physical distancing from others whenever away from home-can be powerful and rewarding motivations. Communications need to make these norms highly visible, and stress how everybody is 'doing the right thing' (without focusing on cheaters, which can backfire). ${ }^{1629} 30$ Failing to comply can also come with negative valuation, for example, physical distancing and handwashing can be considered as good manners, with the implication that those who do not follow risk social opprobrium. ${ }^{31}$

\section{Performance}

Providing advice that is not feasible or requires inordinate sacrifice is likely to be counterproductive. People are more likely to engage in behaviours that require minimum time, physical effort or cognitive load. Any

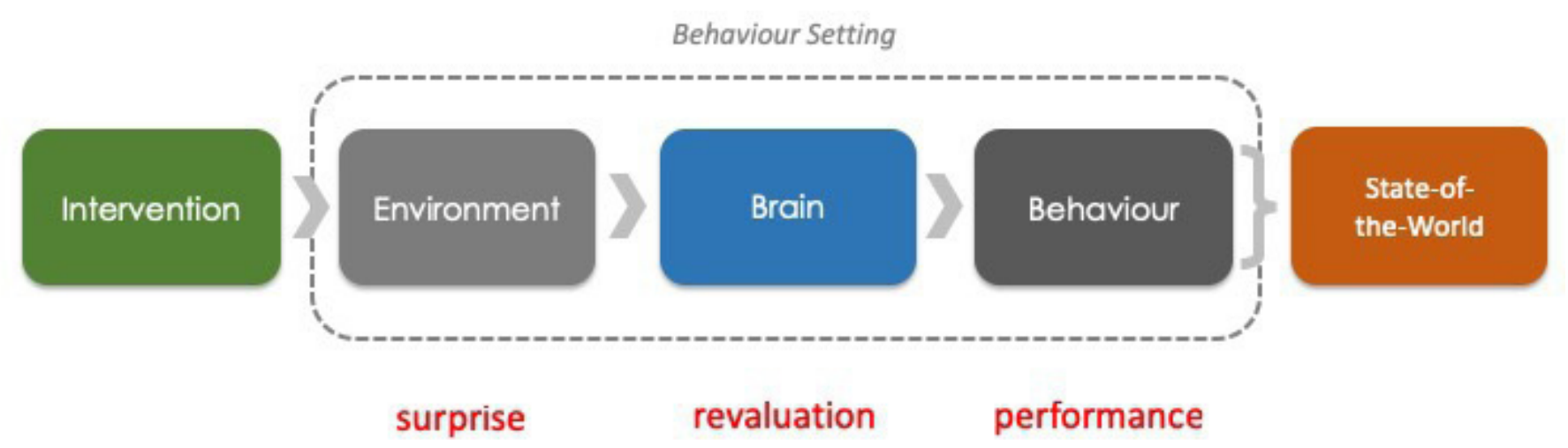
[Inputs]
[Implementation]
[Outputs]
[Outcomes]
[Impact]

Figure 2 Generic theory of change. 
Table 3 Examples of potentially powerful communications materials on COVID-19

\begin{tabular}{|c|c|c|c|}
\hline Name & Concept & Theory of change & Source \\
\hline Corona Virus Alert & $\begin{array}{l}\text { People need to learn about } \\
\text { new virus and how to respond. }\end{array}$ & $\begin{array}{l}\text { Educational, but with a catchy song making the } \\
\text { message memorable; seeing everyone play/sing the } \\
\text { song can promote new norms of behaviour. }\end{array}$ & $\begin{array}{l}\text { Bobi Wine and } \\
\text { Nubian Li (Ugandan } \\
\text { singers) }\end{array}$ \\
\hline Ping Pong Balls & $\begin{array}{l}\text { Visual demonstration of effect } \\
\text { of physical distancing on } \\
\text { transmission. }\end{array}$ & $\begin{array}{l}\text { Seeing consequences instantaneously at a } \\
\text { 'population' level is more comprehensible to our } \\
\text { visually-oriented brains. }\end{array}$ & $\begin{array}{l}\text { Ohio State } \\
\text { Department of } \\
\text { Health }\end{array}$ \\
\hline 'Unstoppables’ & $\begin{array}{l}\text { We should praise some people } \\
\text { for violating the new norms. }\end{array}$ & $\begin{array}{l}\text { Truck drivers move constantly from place to place, } \\
\text { getting close to each other, but are delivering vital } \\
\text { resources to those that need them. }\end{array}$ & $\begin{array}{l}\text { Iveco } \\
\text { (Ogilvy agency) }\end{array}$ \\
\hline $\begin{array}{l}\text { 'Play for the } \\
\text { world' }\end{array}$ & $\begin{array}{l}\text { People who exercise at home } \\
\text { are heroic for ensuring they do } \\
\text { not expose others. }\end{array}$ & $\begin{array}{l}\text { Celebrating personal hardship as socially valuable } \\
\text { makes people more likely to avoid going back into } \\
\text { social contexts. }\end{array}$ & Nike \\
\hline $\begin{array}{l}\text { Universidade do } \\
\text { Futebol }\end{array}$ & $\begin{array}{l}\text { Uncomfortable reminder of } \\
\text { moments when footballers } \\
\text { refused to shake hands. }\end{array}$ & $\begin{array}{l}\text { While refusing to shake hands may seem rude, } \\
\text { nowadays people are actually showing their social } \\
\text { conscience. }\end{array}$ & Liberdade agency \\
\hline
\end{tabular}

means that can be found to reduce the costs of performing the target behaviours will mean that people become more likely to do them. Separating work stations in a factory can make physical distancing easier. Messaging can also help people to figure out how to reduce costs for themselves. For example, ensuring that they have put soap and a bowl of water in the place where they are likely to handwash can reduce the time required. Alternatively, some measures reduce the perception of one of these costs. For example, putting a toy into a children's soap can make kids more likely to wash their hands. ${ }^{32}$ Box 2 has discussed the importance of providing and sustaining WASH infrastructure to make it feasible to follow hygiene advice.

\section{Step 7. Develop a unifying national brand}

With a creative team on board, the first task is to develop a unifying national brand. Communications are only effective when they are trusted. ${ }^{33}$ This is one reason why companies use brands-as a guarantee that they can be held to account for what they produce. ${ }^{34}$ The same is true for national institutions, which have vital roles to play in coordinating social responses to disasters. This trust is precious and government brands need nurturing through crises. Government has to be transparent, by admitting what they know and what they do not know (and a lot still remains unknown about this virus). They should make clear the distinction between science and politics, publish their data, explain their sources and their reasoning for adopting particular strategies.

While the bombardment of materials coming from many directions has raised awareness about the problem of the coronavirus pandemic in most countries, authoritative instructions and advice about what to do about it often remains confused. Governments need to rapidly brand their national campaigns to help to establish credibility and trust and ensure coherence.

A brand usually involves (at minimum) a tagline and a logo. The logo could be based on existing recognised government brands but needs to have new, eye-catching elements. The tagline should very briefly encapsulate the primary insight of the campaign, as set out in the brief. For example, the New Zealand government's COVID-19 brand (https://COVID-19.govt.nz) has a tagline, 'Unite against COVID-19', uses consistent pictorial symbols, has a black and yellow diagonal stripe that alludes to the hazard tape used at an accident scene, employs a simple, friendly typeface and presents information that is clear, precise, pragmatic and accessible.

\section{Step 8. Develop executions employing the most relevant channels for the target audiences}

With a brand established, the next task is to develop creative materials such as ads, posters and other media that embody the brand message and insight. These have to be designed to fit the dominant channels of communication in society, (set out in the brief). Content may take the form of standard TV and radio commercials, or of 'memes' for social media, or of content for existing TV and radio shows to generate discussion and social media sharing.

Communications should employ trusted sources: marketers have long found it profitable to use members of trusted groups, such as doctors or celebrities, as vehicles 
for their messaging. The trusted spokespeople should be recognised by their communities and be relevant to the content of the message. Public health authorities, have a key role here, though they need to be able to speak with confidence and experience. Trying to cover up for failings, rather than acknowledging them tends to be counterproductive of trust since it is hard to disguise from the public ${ }^{35}$ Religious leaders can be trusted figures, but may also spread misinformation and bad advice (as in the case of those who advocate coming together for religious services in the face of government recommendations).

In lockdown conditions, live shooting or recording may create difficulties. However, these can be overcome through CGI, animation and remote conferencing. For messaging to go viral it must be worth sharing, that is, one person who sees the 'meme' must believe it will entertain or enlighten the next person to see it. It must serve as a desirable gift, not just noise. This makes it all the more important that content is surprising, engaging, enlightening and useful to people. For executions to be effective, they should show the target behaviours in their actual settings, and acknowledge the limitations of how far it will be possible to actually carry them out. Table 3 sets out some examples of good communications materials along with some explanation of why they are likely to be effective.

\section{Step 9. Rapidly pretest and continually revise materials}

In an ideal world, new communications content is pretested with samples of target audiences to establish comprehensibility, believability, engagement, likeability and the likelihood that it will be acted on. In emergency conditions, some pretesting, for example, through phone calls with small samples of target audiences, who are asked to view candidate materials online, and respond to them, will still be valuable, allowing course corrections before poorly performing materials are released.

Content will also need to be revised and refreshed often, as the impact of communications diminishes as surprise fades and circumstances evolve (including government policies about what is required at a given stage to control the disease). It may be possible, however, to develop an evolving story line, with engaging characters whose behaviour gradually evolves as the situation develops. An example is the Soul City TV and radio series broadcast from South Africa, anchored in the reality of life in a poor community, which has covered a large range of evolving health and social issues including mother and child health, HIV, cancer and alcohol abuse.

\section{Step 10. Monitor, evaluate and share lessons}

Continual monitoring of the effect of communications on behaviour and behavioural indicators is essential to allow course corrections. For example, in the UK, when it became obvious that public transport use had fallen to some $10 \%$ of prepandemic levels, it was realised that it would not be necessary to focus on reducing the use of public transport in communications. Usage will be continue to be closely monitored as and when lockdown measures are relaxed.

Monitoring of the effect of communications offers particular challenges in pandemic circumstances. Industry, however, is well used to using professional telephone panel survey companies to remotely monitor the effects of their brand-related communications. Such companies are now offering their services in the current pandemic. For example, Geopoll has conducted a remote SMS study of the effects that coronavirus is having in 12 African countries. Ninety-six per cent of participants reported that they had taken measures to protect themselves by increasing handwashing and avoiding public places. Ninety per cent of Rwandans (who are under lockdown) reported staying home while only $57 \%$ of Beninois said that they were. In the sample, trust that government was doing the right thing was highest in Rwanda and lowest in Kenya. ${ }^{36}$

Because these surveys will be repeated at regular intervals they can provide indicators of the success, or otherwise, of government-led communication programmes. It is, of course, recognised that such surveys inevitably oversample the literate and the phone user. To counter this, special surveys could be commissioned targeting the old and the vulnerable, by reaching members of their families. They can also be used to detect the unintended consequences of an intervention, as for example, when, in the above survey, $80 \%$ of respondents said that they were worried that they would not have enough food to eat, mainly due to local market closures.

There are multiple existing and new international fora exchanging information and learning about COVID-19. While joining such fora may not seem a priority at the start of an emergency, COVID-19 is a global problem which will not disappear any time soon and reciprocal efforts to share lessons will pay off eventually for the whole planet.

\section{CONCLUSIONS}

While emergencies are not generally conducive to strategic thinking, in the current COVID-19 pandemic it is vital that country governments take responsibility for the organisation and coordination of national behaviour change strategies (in tandem with taking the actions that make behaviour change possible). In this short guide, we have set out some steps and principles that can help to guide the rapid development of national communications campaigns. While we recognise that every government will want to 'own' its own communication strategy, and fit its content to their particular circumstances, it is still the case that there are general principles of communication that should be followed to ensure maximal impact, because only by following a creative process can truly effective approaches to behaviour change be identified.

This document was written in response to the fact that too few countries currently have strong technical 
expertise and robust institutional structures to be able to conduct professional public health communication programmes, even in the best of times. While the context of an emergency is far from the best of times, the major focus that is currently being placed on behaviour change should remind countries that they will always need this capacity. Every country should have a policy to continually improve their ability to effect strategic health communications in a sustainable fashion, pandemic or no.

Twitter Val Curtis @val23curtis

Acknowledgements The authors would like to thank Dan Ava for the illustration, Paul Deverill and an anonymous reviewer for comments and members of the UK SPI-B committee on COVID-19 for their wisdom.

Contributors VC conceived and wrote a first draft of the article. All coauthors contributed to the paper and have seen and approved the final manuscript.

Funding The authors have not declared a specific grant for this research from any funding agency in the public, commercial or not-for-profit sectors.

Competing interests None declared.

Patient and public involvement Patients and/or the public were not involved in the design, conduct, reporting or dissemination plans of this research.

Patient consent for publication Not required.

Ethics approval Not required

Provenance and peer review Not commissioned; externally peer reviewed.

Data availability statement There are no data in this work.

Open access This is an open access article distributed in accordance with the Creative Commons Attribution Non Commercial (CC BY-NC 4.0) license, which permits others to distribute, remix, adapt, build upon this work non-commercially, and license their derivative works on different terms, provided the original work is properly cited, appropriate credit is given, any changes made indicated, and the use is non-commercial. See: http://creativecommons.org/licenses/by-nc/4.0/.

ORCID iD

Val Curtis http://orcid.org/0000-0001-8994-2878

\section{REFERENCES}

1 White S, Thorseth AH, Dreibelbis R, et al. The determinants of handwashing behaviour in domestic settings: an integrative systematic review. Int J Hyg Environ Health 2020;227:113512.

2 Fleischman DS, Webster GD, Judah G, et al. Sensor recorded changes in rates of hand washing with soap in response to the media reports of the $\mathrm{H} 1 \mathrm{~N} 1$ pandemic in Britain. BMJ Open 2011:1:e000127.

3 Czerniewska A, White S. Hygiene programming during outbreaks: a qualitative case study of the humanitarian response during the Ebola outbreak in Liberia. BMC Public Health 2020;20:154.

4 Curtis VA, Danquah LO, Aunger RV, Planned AR. Planned, motivated and habitual hygiene behaviour: an eleven country review. Health Educ Res 2009;24:655-73.

5 Czerniewska A, Muangi WC, Aunger R, et al. Theory-driven formative research to inform the design of a national sanitation campaign in Tanzania. PLoS One 2019;14:e0221445.

6 Curtis V. Explaining the outcomes of the 'Clean India' campaign: institutional behaviour and sanitation transformation in India. BMJ Glob Health 2019;4:e001892.

7 lyer P, Sara J, Curtis V, et al. The handwashing Handbook. A guide for developing a hygiene promotion program to increase handwashing with soap. Washington, DC: Water and Sanitation Program, 2005

8 Aunger R, Curtis V. Behaviour centred design: towards an applied science of behaviour change. Health Psychol Rev 2016;10:425-46.

9 Sidibe M. Marketing meets mission. Harvard Business Review 2020(May-June 2020): 134.

10 Curtis VA, Garbrah-Aidoo N, Scott B. Ethics in public health research: masters of marketing: bringing private sector skills to public health partnerships. Am J Public Health 2007;97:634-41.

11 Donovan R, Henley N. Social marketing: principles and practice. East Hawthorn: IP Communications, 2003.

12 Mahase E. Covid-19: what is the evidence for cloth masks? BMJ 2020;369:m1422.

13 Rabie T, Curtis V. Handwashing and risk of respiratory infections: a quantitative systematic review. Trop Med Int Health 2006;11:258-67.

14 Fung IC-H, Cairncross S. Effectiveness of handwashing in preventing SARS: a review. Trop Med Int Health 2006;11:1749-58.

15 Freeman MC, Stocks ME, Cumming O, et al. Hygiene and health: systematic review of handwashing practices worldwide and update of health effects. Trop Med Int Health 2014;19:906-16.

16 Curtis V, look Don't, touch don't. The science behind revulsion. Oxford University Press: Oxford, 2013.

17 Judah G, Aunger R, Schmidt W-P, et al. Experimental pretesting of hand-washing interventions in a natural setting. Am J Public Health 2009;99 Suppl 2:S405-11.

18 Aunger R, Schmidt W-P, Ranpura A, et al. Three kinds of psychological determinants for hand-washing behaviour in Kenya. Soc Sci Med 2010;70:383-91.

19 Aunger R, Greenland K, Ploubidis G, et al. The determinants of reported personal and household hygiene behaviour: a multi-country study. PLoS One 2016;11:e0159551.

20 Curtis V, Look Don't, Touch Don't. Don't Eat: The Science Behind Revulsion. Chicago: University of Chicago Press, 2013.

21 Brown T. Change by design: how design thinking transforms organizations and inspires innovation. New York: HarperCollins, 2009.

22 Bonell C, Jamal F, Melendez-Torres GJ, et al. 'Dark logic': theorising the harmful consequences of public health interventions. J Epidemiol Community Health 2015;69:95-8.

23 Friston K. The free-energy principle: a unified brain theory? Nat Rev Neurosci 2010;11:127-38.

24 Schultz W. Predictive reward signal of dopamine neurons. $J$ Neurophysiol 1998;80:1-27.

25 Schultz W. Behavioral theories and the neurophysiology of reward. Annu Rev Psychol 2006:57:87-115.

26 Gintis H, Bowles S, Boyd RT, et al. Moral sentiments and material interests: the foundations of cooperation in economic life: MIT press, 2005.

27 Schnall S, Roper J, Fessler DMT. Elevation leads to altruistic behavior. Psychol Sci 2010;21:315-20.

28 Van Bavel JJ, Boggio P, Capraro V, et al. Using social and behavioural science to support COVID-19 pandemic response, 2020

29 Bicchieri C. Norms in the wild: how to diagnose, measure, and change social norms: Oxford university press, 2016.

30 Goldstein NJ, Cialdini RB, Griskevicius V. A room with a viewpoint: using social norms to motivate environmental conservation in hotels. $J$ Consum Res 2008;35:472-82.

31 Curtis V. Manners maketh man: how disgust shaped human evolution. New Scientist 2013;219:28-9.

32 Watson J, Dreibelbis R, Aunger R, et al. Child's play: harnessing play and curiosity motives to improve child handwashing in a humanitarian setting. Int J Hyg Environ Health 2019;222:177-82.

33 Mercier H, Sperber D. The enigma of reason: Harvard University press, 2017.

34 Keller KL, Brexendorf TO. Measuring brand equity. Handbuch Markenführung: Springer, 2019: 1409-39.

35 Bonell C, Michie S, Reicher S, et al. Harnessing behavioural science in public health campaigns to maintain 'social distancing in response to the COVID-19 pandemic: key principles. J Epidemiol Community Health 2020;74:617-9.

36 Geopoll. Coronavirus in sub-Saharan Africa: |How Africans in 12 nations are reponding to the covid-19 outbreak, 2020. 